\title{
AUTHORS' RESPONSE (JUY 6,2017$)$ TO THE LETTER TO THE EDITOR CONCERNING THE PAPER "IMPACT OF ROAD TRAFFIC NOISE ON SLEEP DISTURBANCES AND ATTENTION DISORDERS AMONGST SCHOOL CHILDREN LIVING IN UPPER SILESIAN INDUSTRIAL ZONE, POLAND"
}

Dear Editor,

First of all, we appreciate the interest of Dr. Kawada [1] that has been aroused by our article that had been published in the "International Journal of Occupational Medicine and Environmental Health" 2017;30(3):511-20 [2]. Authors are aware of limitations of their research, which has been widely discussed in the article. We also agree with Dr. Kawada who has raised issues that require further research, especially with more precise measurements of exposure to the noise, and more reliable outcomes. In the case of the lack of such precise data, surrogates of the exposure are often used in the field of epidemiology, of course with several limitations, which has been presented and discussed in our article.

Key words:

Sleep, Child, Noise, Attention, Transportation, Automobiles

\section{REFERENCES}

1. Kawada T. Letter to the Editor (May 17, 2017) concerning the paper "Impact of road traffic noise on sleep disturbances and attention disorders amongst school children living in Upper Silesian Industrial Zone, Poland”. Int J Occup Med
Environ Health. 2018;31(1):125-6, https://doi.org/10.13075/ ijomeh.1896.01216.

2. Skrzypek M, Kowalska M, Czech EM, Niewiadomska E, Zejda JE. Impact of road traffic noise on sleep disturbances and attention disorders amongst school children living in Upper Silesian Industrial Zone, Poland. Int J Occup Med Environ Health. 2017;30(3):511-20, https://doi.org/10.13075/ijomeh.1896.00823.

Michał Skrzypek ${ }^{1}$, Małgorzata Kowalska², Elżbieta M. Czech ${ }^{1}$, Ewa Niewiadomska ${ }^{1}$, and Jan E. Zejda ${ }^{2}$

Medical University of Silesia, Katowice, Poland ${ }^{1}$ School of Public Health in Bytom, Department of Biostatistics

${ }^{2}$ Medical Faculty in Katowice, Department of Epidemiology

Corresponding author: M. Skrzypek Medical University of Silesia School of Public Health, Department of Biostatistics Piekarska 18, 41-902 Bytom, Poland (e-mail: mskrzypek@sum.edu.pl)

This work is available in Open Access model and licensed under a Creative Commons Attribution-NonCommercial 3.0 Poland License - http://creativecommons.org/ licenses/by-nc/3.0/pl/deed.en. 